\title{
ANALISIS DESAIN TOJOK SEBAGAI ALAT SORTASI TBS KELAPA SAWIT DI LOADING RAMP
}

\author{
Anizar $^{*}$ \\ Departemen Teknik Industri, Fakultas Teknik, Universitas Sumatera Utara, \\ Jl. Almamater, Kampus USU, Medan 20155
}

\begin{abstract}
Abstrak
Proses sortasi tandan buah segar (TBS) di loading ramp dilakukan oleh operator laki-laki berupa kegiatan menurunkan TBS dari truk, mensortir TBS dan menaikkan TBS mentah ataupun busuk ke truk dengan berat TBS berkisar $20 \mathrm{~kg}$ hingga $25 \mathrm{~kg}$ dengan menggunakan tojok. Tojok merupakan sebatang besi berujung tajam dengan pegangan berbentuk $\mathrm{T}$ sepanjang $85 \mathrm{~cm}$, diameter batang $2,5 \mathrm{~cm}$ dan lebar pegangan $15 \mathrm{~cm}$. Desain tojok aktual menyebabkan operator sortasi memiliki postur tubuh bungkuk, leher tunduk, dan lutut tertekuk secara berulang-ulang selama satu hari. Operator mengeluhkan rasa sakit pada otot (MSDs) terutama pada pinggang, lengan atas kanan, punggung, lengan bawah kanan, tangan kanan, dan betis kanan. Keluhan MSDs yang dialami operator semakin meningkat sebanding dengan jumlah truk yang harus dibongkar TBS nya dalam sehari. Metode yang digunakan adalah observasi lapangan dan wawancara dengan kuesioner terhadap operator sortasi sejumlah 8 orang. Penyebaran kuesioner terbuka untuk memperoleh atribut tojok diberikan kepada 30 orang responden. Hasil yang diperoleh adalah tojok terbuat dari bahan stainless steel, mata tojok terbuat dari besi AS, pegangan berbentuk segitiga, pembatas batang tojok dengan mata tojok berjarak $10 \mathrm{~cm}$ dan pegangan tambahan berjarak $30 \mathrm{~cm}$ dari handle. Panjang tojok $97,1 \mathrm{~cm}$, lebar pegangan tojok $11 \mathrm{~cm}$ dan diameter batang tojok $2,77 \mathrm{~cm}$
\end{abstract}

Kata kunci : desain; ergonomis; sortasi; tojok; TBS

\begin{abstract}
Design Analysis of Tojok as Sorting Tools TBS Palm Oil in Loading Ramp. TBS Sorting process in loading ramp, done by male operators, is the act of bringing down the TBS from the truck, sorting TBS and bringing the raw or rotten TBS back into the truck and the TBS weigh around $20 \mathrm{~kg}$ to $25 \mathrm{~kg}$ using tojok. Tojok is a steel bar with a sharp end and a handle forming T-shape at the other end that. The dimension is $85 \mathrm{~cm}$ long, $2.5 \mathrm{~cm}$ in diameter, and $15 \mathrm{~cm}$ for handle width. The actual tojok design make the operators to bent their back, flex their kness, and bowed their head for multiple times in a day. Operators are complaining about pain in their muscles (MSDs), especialy in waist, upper arm, back, lower right arm, and right calf. The MSDs pain felt by operators increase as they discharged more TBS from the truck throughout the day. The method used in finding this information is field observation and interview with 8 operators. The result is that tojok is made of stainless steel, its sharp end is made of AS steel, its handle's shape is triangle, the length from its sharp end to its bar border is $10 \mathrm{~cm}$, and the distance from the handle to another extra handle is $30 \mathrm{~cm}$. The tojok length is $97.1 \mathrm{~cm}$, its handle width is $11 \mathrm{~cm}$, and the diameter is $2.77 \mathrm{~cm}$
\end{abstract}

Keywords: design; ergonomics; sorting; tojok; TBS

\footnotetext{
${ }^{*)}$ Penulis Korespondensi. email: anizar_usu@yahoo.co.id
} 


\section{Pendahuluan}

Pabrik kelapa sawit menghasilkan Crude Palm Oil (CPO) yang diolah dari buah kelapa sawit disebut sebagai tandan buah segar (TBS). Penelitian pada industri kelapa sawit difokuskan pada stasiun sortasi dimana aktivitas manual mendominasi. Kualitas CPO yang dihasilkan sangat dipengaruhi oleh proses penyortiran kelapa sawit yang dilakukan operator secara manual dengan fasilitas kerja yang sangat sederhana. Proses sortasi TBS di loading ramp dilakukan oleh operator laki-laki berupa kegiatan memilah TBS sesuai dengan fraksi yang telah ditetapkan. TBS dipindahkan ke dalam lori sehingga operator memiliki postur kerja berdiri dengan tubuh membungkuk dan leher menunduk sehingga otot bekerja statis. Postur kerja berdiri dan membungkuk dilakukan secara bergantian selama 10 jam setiap hari selama 6 hari dalam seminggu. Kondisi ini dilakukan secara berulang-ulang (repetitif) setiap harinya dengan fasilitas yang tidak nyaman dan tidak sesuai antropometri tubuh pekerja.

Pekerjaan dengan beban yang berat dan frekuensi tinggi serta dilakukan secara berulang (repetitif) menimbulkan keluhan rasa sakit pada operator. Keluhan disebabkan otot menerima tekanan akibat gaya dari pengangkutan beban kerja fisik terus menerus secara berulang (repetitif) tanpa memperoleh kesempatan untuk relaksasi. Postur kerja tidak alamiah, peregangan otot berlebihan, getaran dengan frekuensi tinggi, dan tekanan langsung pada jaringan otot lunak dapat menyebabkan keluhan rasa sakit (Iridiastasi, 2014).

Kelelahan dan keluhan nyeri yang timbul merupakan keluhan muskuloskeletal dimana keluhan pada bagian-bagian otot skeletal yang dirasakan oleh seseorang mulai dari keluhan sangat ringan sampai sangat sakit. Apabila otot menerima beban statis secara berulang dan dalam waktu yang lama, akan dapat menyebabkan keluhan berupa kerusakan pada sendi, ligament dan tendon. Keluhan otot terdiri dari keluhan sementara yaitu keluhan otot yang terjadi pada saat otot menerima beban statis, namun demikian keluhan tersebut akan segera hilang apabila pembebanan dihentikan, dan keluhan menetap dimana walaupun pembebanan kerja telah dihentikan, namun rasa sakit pada otot masih terus berlanjut (Tarwaka, 2004).

Karmila (2014) melakukan penelitian pada kegiatan sortasi TBS di perusahaan perkebunan kelapa sawit untuk mengetahui keluhan rasa sakit operator. Penilaian menggunakan Standard Nordic Questionairre (SNQ) diketahui bahwa operator mengeluhkan rasa sakit pada pinggang $(13,79 \%)$, lengan atas $(10,34 \%)$, punggung $(6,89 \%)$, bahu kanan $(6,21 \%)$ dan betis kanan $(5,51 \%)$.

Surya (2014) melakukan penelitian pada kegiatan pasca panen kelapa sawit di Desa Bagan Jaya, Kabupaten Indragiri Hilir. Provinsi Riau. Aktivitas petani sawit mengangkut tandan buah segar (TBS) kelapa sawit dan memuatnya ke truk

Jurnal Teknik Industri, Vol. X, No. 3, September 2015 menimbulkan keluhan fisik. Peneliti melakukan perbaikan terhadap rancangan tojok didasarkan pada kebutuhan petani. Atribut yang diperoleh adalah desain ukuran, desain bentuk, kualitas bahan, pemilihan bahan baku, jenis bahan, tebal bahan, desain handle, diameter handle, lebar handle, panjang handle, panjang ukuran produk, proses pemakaian dan diameter produk. Penilaian keluhan petani terhadap rancangan tojok baru dengan kuisioner Nordic Body Map diketahui adanya penurunan keluhan muskuloskeletal sebesar 27,81\%.

Pengamatan dilakukan pada proses sortasi TBS di loading ramp pabrik kelapa sawit dengan menggunakan tojok. Gambar-1 menunjukkan salah satu postur kerja operator menurunkan TBS dari truk dengan menggunakan tojok.

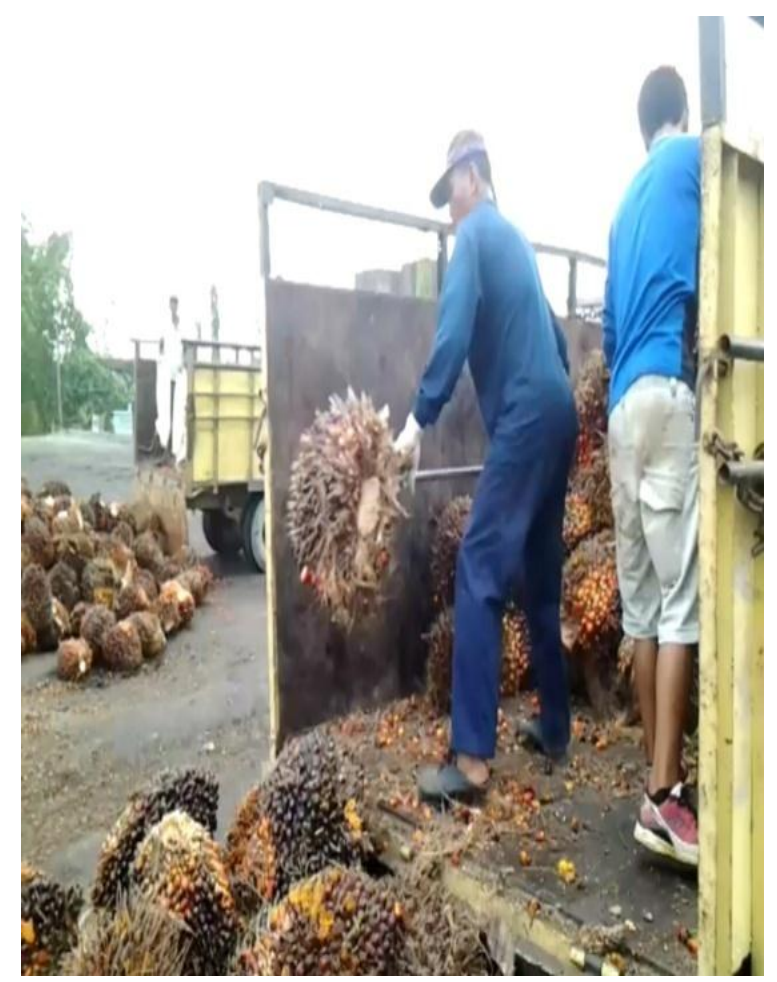

Gambar 1. Operator menurunkan TBS

Operator melakukan proses sortasi di loading ramp dengan kegiatan menurunkan TBS dari truk, mensortir TBS sesuai dengan ketentuan fraksi dan menaikkan TBS mentah ataupun busuk ke truk dengan berat TBS berkisar $20 \mathrm{~kg}$ hingga $25 \mathrm{~kg}$. Kegiatan sortasi TBS dimulai pukul 8 pagi hingga pukul 7 malam dengan istirahat selama 1,5 jam pada pukul 12 siang.

Postur kerja operator pada saat menurunkan TBS dari truk adalah batang tubuh bungkuk dengan sudut $>60^{\circ}$ untuk mencucukkan batang tojok ke TBS, mengangkat TBS dengan batang tubuh bungkuk dan kaki membentuk sudut $30-60^{\circ}$ dan melemparkan TBS ke lantai loading ramp. Kegiatan tersebut dilakukan secara berulang dan terus-menerus sehingga seluruh TBS sudah diturunkan dari truk. Postur kerja operator 
pada saat mensortir TBS di loading ramp adalah batang tubuh bungkuk dengan sudut $20^{\circ}$, leher membentuk sudut $>20^{\circ}$, kaki bertumpu pada satu kaki lurus dengan lutut tertekuk $>60^{\circ}$. Postur kerja operator pada saat menaikkan TBS ke truk adalah batang tubuh bungkuk dengan sudut $>60^{\circ}$ untuk mencucukkan batang tojok ke TBS, mengangkat TBS dengan batang tubuh bungkuk dan kaki membentuk sudut $30-60^{\circ}$ dan melemparkan TBS ke truk dengan kaki lurus.

Pembahasan akan dilakukan secara mendalam berkaitan dengan desain tojok yang selama ini dipergunakan oleh operator sortasi TBS. Atribut tojok dan karakteristik tojok yang diinginkan oleh operator sortasi TBS merupakan dasar untuk mendapatkan rancangan tojok yang ergonomis.

\section{Bahan dan Metode}

Penelitian dilakukan di loading ramp PT. Perkebunan Nusantara II Kebun Sawit Seberang, Kabupaten Langkat, Propinsi Sumatera Utara. Subjek pada penelitian ini adalah operator sortasi sejumlah 8 orang yang menggunakan tojok sebagai alat sortasi dan material hadling TBS. Seluruh operator sortasi berjenis kelamin laki-laki. Penyebaran kuesioner terbuka untuk memperoleh atribut tojok diberikan kepada 30 orang responden yaitu operator yang ada di loading ramp.

Metode yang digunakan pada penelitian ini adalah observasi lapangan dan wawancara dengan menggunakan kuesioner. Observasi lapangan dilakukan di loading ramp untuk :

1. Mengukur dimensi tojok aktual dengan meteran.

2. Mengukur sudut tubuh operator dengan goniometer.

3. Mengukur dimensi tubuh (antropometri) operator dengan Human Body Martin sebagai acuan untuk dimensi tojok yang akan dirancang.

4. Mengidentifikasi keluhan rasa sakit pada bagian tubuh operator dengan Standard Nordic Questionairre $(S N Q)$ dengan kategori sangat sakit diberi bobot 3, sakit diberi bobot 2, agak sakit diberi bobot 1 dan tidak sakit diberi bobot 0 .

5. Penyebaran kuisioner untuk mengidentifikasi keinginan operator menjadi atribut tojok.

6. Penyebaran kuisioner terbuka dan tertutup untuk mengetahui karakteristik tojok yang diinginkan operator

\section{Hasil dan Pembahasan \\ Atribut Tojok Aktual dan Rancangan}

Tojok adalah semacam tombak dengan handle berbentuk $\mathrm{T}$ yang digunakan pada proses sortasi TBS di kebun kelapa sawit dan pabrik kelapa sawit. Tojok aktual yang digunakan saat ini terbuat dari besi untuk batang tojok dan besi As untuk mata tojok. Tojok dengan panjang batang $85 \mathrm{~cm}$, diameter batang 2,5 $\mathrm{cm}$, lebar pegangan $15 \mathrm{~cm}$ dan panjang mata tojok 15 $\mathrm{cm}$ sebagaimana ditunjukkan pada Gambar-2. Operator sortasi TBS secara terus-menerus selama jam kerja akan bekerja menurunkan TBS dari truk, Jurnal Teknik Industri, Vol. X, No. 3, September 2015 mensortir TBS di loading ramp dan menaikkan kembali TBS yang busuk ataupun mentah ke truk sehingga beban kerja berdampak pada pinggang, lengan atas kanan, punggung, lengan bawah kanan, tangan kanan, dan betis kanan.

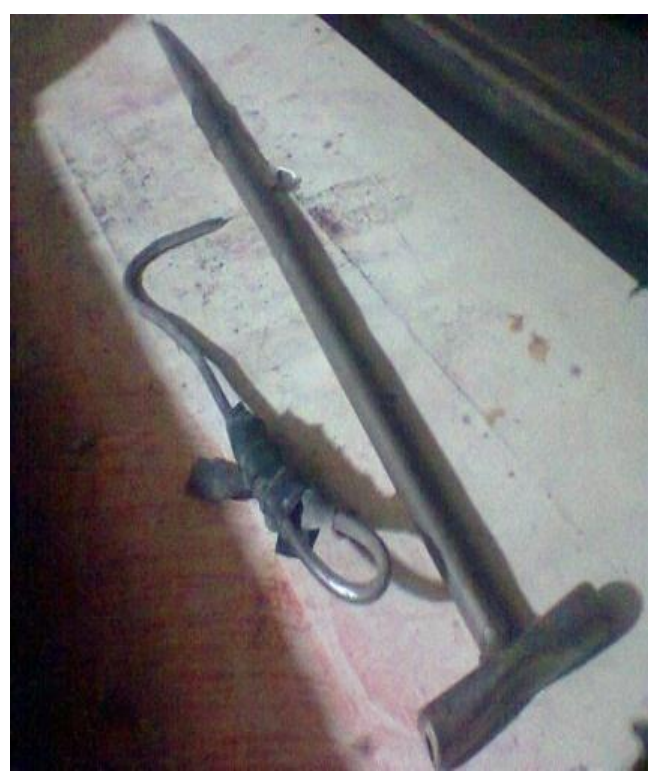

Gambar 2. Tojok

Operator sortasi TBS sering berhenti sejenak setelah melakukan kegiatan untuk melakukan peregangan otot. Penyebaran kuesioner dilakukan terhadap 30 orang operator sortasi TBS tentang kriteria atribut tojok yang diinginkan sehingga dapat mereduksi keluhan MSDs yang dirasakan terdapat pada Tabel 1.

Tabel 1. Rekapitulasi Kuesioner Terbuka Tojok

\begin{tabular}{|c|c|c|c|c|}
\hline No. & Pertanyaan & $\begin{array}{l}\text { Jawaban } \\
\text { responden }\end{array}$ & $\begin{array}{l}\text { Jum } \\
\text { lah }\end{array}$ & Modus \\
\hline \multirow[t]{3}{*}{1} & $\begin{array}{l}\text { Bahan } \\
\text { batang tojok }\end{array}$ & $\begin{array}{l}\text { Stainless } \\
\text { steel }\end{array}$ & 27 & $\begin{array}{c}\text { Stainless } \\
\text { steel }\end{array}$ \\
\hline & & Kayu & 3 & \\
\hline & & Total & 30 & \\
\hline \multirow[t]{2}{*}{2} & $\begin{array}{l}\text { Bahan } \\
\text { pegangan }\end{array}$ & $\begin{array}{l}\text { Stainless } \\
\text { steel }\end{array}$ & 30 & $\begin{array}{c}\text { Stainless } \\
\text { steel }\end{array}$ \\
\hline & & Total & 30 & \\
\hline \multirow[t]{2}{*}{3} & $\begin{array}{l}\text { Bahan mata } \\
\text { tojok }\end{array}$ & $\begin{array}{l}\text { Stainless } \\
\text { steel }\end{array}$ & 30 & \\
\hline & & Total & 30 & \\
\hline \multirow[t]{5}{*}{4} & Bahan & Karet & 7 & \\
\hline & Pelapis & Handuk & 14 & Handuk \\
\hline & Pegangan & Busa & 6 & \\
\hline & & $\begin{array}{l}\text { Sarung } \\
\text { tangan }\end{array}$ & 3 & \\
\hline & & Total & 30 & \\
\hline \multirow[t]{4}{*}{5} & Bentuk & Tabung & 7 & \\
\hline & Pegangan & Segitiga & 16 & Segitiga \\
\hline & & Oval & 7 & \\
\hline & & Total & 30 & \\
\hline
\end{tabular}




\begin{tabular}{cllcl}
\hline 6 & Bentuk & Tabung & 21 & Tabung \\
& Pegangan & Oval & 9 & \\
& Tambahan & Total & 30 & \\
& Lebar & 11,5 & 2 & \\
& Pegangan & 11 & 14 & $11 \mathrm{~cm}$ \\
& & 10 & 8 & \\
& & 9,5 & 8 & \\
8 & Panjang & Total & 30 & \\
& Tojok & 120 & 3 & \\
& & 110 & 5 & \\
& & 100 & 13 & $100 \mathrm{~cm}$ \\
& & 95 & 9 & \\
\hline
\end{tabular}

Pada Tabel 1 terlihat bahwa 90\% responden memilih atribut batang tojok terbuat dari stainless steel sedangkan tojok aktual terbuat dari besi. Seluruh responden memilih atribut bahan untuk pegangan dan mata tojok terbuat dari stainless steel. Atribut bahan pelapis untuk pegangan (handle) tojok dipilih terbuat dari kain handuk oleh $47 \%$ responden untuk menyerap keringat di telapak tangan sehingga tidak licin saat digunakan. Segitiga dipilih oleh $53 \%$ responden sebagai atribut bentuk pegangan tojok sehingga tangan dapat menggenggam pegangan tojok secara sempurna dan keluhan rasa sakit pada telapak tangan saat melakukan proses sortasi TBS dengan tojok aktual dapat dihilangkan. Atribut lebar pegangan yang diinginkan oleh $47 \%$ responden adalah sepanjang 11 $\mathrm{cm}$. Pegangan tambahan berbentuk tabung dipilih oleh $70 \%$ responden sehingga pada saat tangan kanan operator memegang batang tojok maka tangan kiri dapat membantu dengan memegang pegangan tambahan. Atribut panjang tojok sepanjang $100 \mathrm{~cm}$ diinginkan oleh $43 \%$ responden sehingga kesulitan untuk menaikkan kembali TBS yang tidak sesuai fraksi ke truk dengan menggunakan tojok aktual sepanjang $85 \mathrm{~cm}$ dapat diatasi.

\section{Keluhan Muskuloskeletal (MSDs)}

Proses sortasi TBS cenderung menimbulkan keluhan rasa sakit pada beberapa bagian tubuh operator. Rasa sakit dialami setelah operator menyelesaikan seluruh pekerjaan mensortir TBS selama satu hari. Sebagian besar operator yaitu $87,5 \%$ mengeluhkan rasa sakit pada pinggang dengan kriteria sangat sakit yang mencapai $50 \%$ dan kriteria sakit sebesar $37,5 \%$. Keluhan operator dengan kriteria sakit dialami juga pada bagian lengan atas kanan dan punggung masing-masing sebesar 37,5\%. Hal ini mengindikasikan bahwa keluhan MSDs disebabkan oleh proses sortasi TBS dengan menggunakan tojok. Desain tojok yang ada saat ini menyebabkan operator yang melakukan proses sortasi memiliki postur tubuh bungkuk, leher tunduk, dan lutut tertekuk secara berulang-ulang selama satu hari. Keluhan MSDs yang dialami operator semakin meningkat sebanding dengan jumlah truk yang harus dibongkar TBS nya dalam sehari. Hasil pengukuran diameter genggaman tangan operator ditunjukkan pada Tabel 2 .
Tabel 2. Diameter Genggaman

\begin{tabular}{ccc}
\hline No. & $\begin{array}{c}\text { Diameter } \\
\text { Genggaman } \\
\text { Operator }(\mathbf{c m})\end{array}$ & $\begin{array}{c}\text { Selisih } \\
\text { Diameter } \\
\text { Genggaman } \\
(\mathbf{c m})\end{array}$ \\
\hline 1 & 3,5 & 1,0 \\
2 & 3,0 & 0,5 \\
3 & 3,0 & 1,0 \\
4 & 3,7 & 1,2 \\
5 & 3,9 & 1,4 \\
6 & 3,5 & 1,0 \\
7 & 4,0 & 1,5 \\
8 & 3,5 & 1,0 \\
\hline $\mathrm{X}$ & 3,51 & 1,075 \\
\hline
\end{tabular}

Tabel 2 menunjukkan bahwa diameter tojok aktual sebesar $2,5 \mathrm{~cm}$ adalah lebih kecil daripada diameter genggaman tangan operator dengan selisih rata-rata sebesar $1,075 \mathrm{~cm}$ sehingga penggunaannya tidak menimbulkan rasa sakit pada tangan operator sortasi TBS. Namun pegangan yang berbentuk $T$ menimbulkan masalah pada operator saat melakukan proses sortasi diamana tangan kanan operator tidak dapat menggenggam pegangan tojok secara sempurna karena terhalang oleh batang tojok. Operator memposisikan batang tojok pada celah antara jari telunjuk dan jari tengah sehingga pegangan sepanjang $15 \mathrm{~cm}$ dengan diameter $2 \mathrm{~cm}$ berada di telapak tangan kanan. Kondisi ini mengakibatkan telapak tangan kanan operator menjadi keras (kapalan) yang kemudian me1.nyebabkan luka. Operator membantu proses pensortiran dengan meletakkan tangan kiri pada batang tojok sehingga dapat menopang beban TBS yang akan dipindahkan.

\section{Redesain Tojok Ergonomis}

Redesain tojok dilakukan dengan mengadakan perubahan terhadap bentuk dan dimensi pegangan (handle) tojok, panjang dan diameter batang tojok serta pengadaan pegangan tambahan untuk tangan kiri. Pengukuran dilakukan terhadap tinggi siku berdiri (TSB) untuk menentukan panjang tojok, pangkal ke tangan (PPt) untuk menentukan diameter pegangan, jangkauan tangan (JT) untuk menentukan jangkauan terjauh yang dapat dicapai, lebar tangan (LT) untuk menentukan lebar pegangan tojok dan genggaman tangan (DG) untuk menentukan diameter batang tojok.

Pengumpulan data diameter genggaman tangan dilakukan terhadap 42 orang yang terdiri dari 8 operator sortasi TBS di loading ramp ditambah dengan 34 data dimensi tubuh dari Laboratorium Ergonomi dan Analisa Perancangan Kerja di Departemen Teknik Industri, Fakultas Teknik USU. Langkah yang dilakukan adalah:

1. Penentuan nilai rata-rata dan standar deviasi dimensi tubuh operator (Tabel 3). 
Tabel 3. Nilai Dimensi Tubuh Operator

\begin{tabular}{lccc}
\hline Dimensi Tubuh & $\sum \mathbf{X}$ & $\mathbf{X}$ & $\boldsymbol{\Sigma}$ \\
\hline TSB & $4.079,1$ & 97,1 & 5,2 \\
LT & 360,4 & 9,0 & 0,8 \\
DG & 128,3 & 3,1 & 0,2 \\
\hline
\end{tabular}

2. Nilai minimum data dimensi tubuh operator diperoleh dengan mengurutkan dari data terkecil dan sebaliknya (Tabel 4).

Tabel 4. Nilai Min-Max Dimensi Tubuh Operator

\begin{tabular}{lcc}
\hline Dimensi Tubuh & $\mathbf{X}_{\min }$ & $\mathbf{X}_{\max }$ \\
\hline TSB & 86,7 & 106,7 \\
LT & 7,2 & 10,1 \\
DG & 2,7 & 3,5 \\
\hline
\end{tabular}

3. Uji keseragaman data menggunakan peta kontrol menggunakan tingkat kepercayaan 95\% dan tingkat ketelitian 5\% diperoleh nilai batas kontrol atas (BKA) dan batas kontrol bawah (BKB). Tabel 5 menampilkan data setelah dilakukan beberapa kali revisi.

Tabel 5. Hasil Uji Keseragaman Data

\begin{tabular}{lccc}
\hline Dimensi Tubuh & BKA & BKB & Hasil \\
\hline TSB & 106,7 & 86,6 & Seragam \\
LT & 10,5 & 7,6 & Seragam \\
DG & 3,5 & 2,6 & Seragam \\
\hline
\end{tabular}

4. Uji normalitas data dilakukan karena desain tojok menggunakan konsep persentil. Metode Kolmogorov-Smirrnov digunakan dengan bantuan software SPSS 17 dan diperoleh hasil bahwa data telah berdistribusi normal (Tabel 6).

Tabel 6. Hasil Uji Keseragaman Data

\begin{tabular}{lcc}
\hline $\begin{array}{l}\text { Dimensi } \\
\text { Tubuh }\end{array}$ & Nilai & Hasil \\
\hline TSB & 0,452 & Normal \\
LT & 0,722 & Normal \\
DG & 0,825 & Normal \\
\hline
\end{tabular}

5. Penentuan nilai persentil dilakukan terhadap data diameter genggaman tangan dengan ketentuan persentil 5, 50 dan 95. Nilai persentil yang diperoleh ditunjukkan oleh Tabel 7.

Tabel 7. Nilai Persentil 5, 50 dan 95

\begin{tabular}{lcccc}
\hline $\begin{array}{l}\text { Dimensi } \\
\text { tubuh }\end{array}$ & $\mathbf{X}$ & $\mathbf{P}_{\mathbf{5}}$ & $\mathbf{P}_{\mathbf{5 0}}$ & $\mathbf{P}_{\mathbf{9 5}}$ \\
\hline TSB & 97,1 & 88,55 & 97,1 & 105,65 \\
LT & 9,0 & 7,68 & 9,0 & 10,32 \\
DG & 3,1 & 2,77 & 3,1 & 3,43 \\
\hline
\end{tabular}

Jurnal Teknik Industri, Vol. X, No. 3, September 2015
Dimensi tubuh operator yang digunakan pada penelitian ini adalah panjang tojok menggunakan data TSB persentil 50 dengan nilai $97,1 \mathrm{~cm}$. Persentil 50 dipilih sehingga operator sortasi TBS yang memiliki tinggi siku berdiri lebih kecil dapat menggunakan tojok dengan nyaman. Lebar pegangan (handle) tojok menggunakan data LT persentil 95 dengan nilai 10,32 $\mathrm{cm}$ dan dibulatkan menjadi $11 \mathrm{~cm}$. Penggunaan persentil 95 menyebabkan seluruh operator sortasi TBS dapat memegang handle tojok dengan nyaman sebab panjang pangkal ke tangan (PPt) operator memiiki nilai maksimal $10,18 \mathrm{~cm}$. Diameter genggaman tojok menggunakan data persentil 5 dengan nilai $2,77 \mathrm{~cm}$ sehingga Persentil 5 dipilih sehingga operator sortasi TBS yang memiliki diamater genggaman tangan lebih kecil dapat menggunakan tojok dengan nyaman. Operator dengan diameter genggaman tangan yang lebih panjang tetap dapat menggunakan tojok hasil rancangan.

Rancangan tojok yang baru memiliki handle berbentuk segitiga dan pembatas antara batang tojok dengan mata tojok dengan jarak $10 \mathrm{~cm}$ sehingga tandan buah segar (TBS) kelapa sawit tidak masuk terlalu dalam ke batang tojok. Pegangan tambahan pada batang tojok dengan jarak $30 \mathrm{~cm}$ dari handle sebagai pegangan untuk tangan kiri operator saat mengangkat dan memindahkan TBS. Tabel-8 menunjukkan perbandingan desain rancangan tojok aktual dengan tojok usulan.

Tabel 8. Perbandingan Desain Tojok Aktual dan Tojok Hasil Rancangan

\begin{tabular}{|c|c|c|c|}
\hline No & Dimensi & Aktual & Rancangan \\
\hline 1 & Bahan tojok & Besi & $\begin{array}{l}\text { Stainless } \\
\text { steel }\end{array}$ \\
\hline 2 & Bentuk pegangan & $\mathrm{T}$ & Segitiga \\
\hline 3 & Lebar pegangan & $15 \mathrm{~cm}$ & $11 \mathrm{~cm}$ \\
\hline 4 & Pelapis pegangan & Tidak ada & handuk \\
\hline 5 & Pegangan tambahan & Tidak ada & $\begin{array}{l}\text { Ada, jarak } \\
30 \mathrm{~cm} \text { dari } \\
\text { pegangan } \\
\text { utama }\end{array}$ \\
\hline 6 & Panjang tojok & $85 \mathrm{~cm}$ & $100 \mathrm{~cm}$ \\
\hline 7 & $\begin{array}{l}\text { Pembatas mata } \\
\text { tojok }\end{array}$ & Tidak ada & $\begin{array}{l}\text { Ada, jarak } \\
20 \mathrm{~cm} \text { dari } \\
\text { mata tojok }\end{array}$ \\
\hline
\end{tabular}

Penggunaan tojok hasil rancangan oleh operator sortasi TBS untuk kegiatan sortasi menunjukkan terjadinya penurunan keluhan rasa sakit yang terlihat dari turunnya skor. Skor untuk tubuh bagian kanan turun dari skor 10 menjadi skor 7 dan untuk tubuh bagian kiri dari skor 11 menjadi skor 5. Penurunan skor disebabkan adanya tambahan pegangan berlapis handuk untuk tangan kiri pada saat proses sortasi TBS dilakukan sehingga tangan kiri tidak lagi memegang batang tojok yang licin.

Namun penggunaan tojok hasil rancangan untuk kegiatan menaikkan TBS ke atas truk menunjukkan 
hal yang sebaliknya yaitu bertambahnya keluhan rasa sakit dengan peningkatan skor yaitu untuk tubuh bagian kanan dari skor 9 menjadi skor 10 dan untuk tubuh bagian kiri dari skor 8 menjadi skor 11 .

\section{Kesimpulan}

Proses sortasi TBS kelapa sawit di loading ramp menimbulkan keluhan MSDs mulai dari rasa sakit hingga sangat sakit pada pinggang, punggung, dan lengan atas kanan. Keluhan MSDs operator semakin meningkat sebanding dengan jumlah truk yang harus dibongkar TBS nya dalam satu hari.

Desain tojok aktual menyebabkan operator sortasi memiliki postur kerja bungkuk, leher tunduk, dan lutut tertekuk secara berulang-ulang selama satu hari.

Rancangan desain tojok diperbaiki dengan merubah bentuk pegangan (handle) dari bentuk $\mathrm{T}$ menjadi segitiga dan diberi pelapis dari handuk sehingga keluhan licin dan kapalan pada telapak tangan tidak dirasakan lagi. Operator dapat menggenggam tojok dengan sempurna. Tojok diberi tambahan pegangan untuk tangan kiri sehingga pada saat mengangkat dan memindahkan TBS dapat lebih mudah.

Perbaikan desain tojok berupa menambah panjang tojok, memberi pembatas antara batang tojok dengan mata tojok, memberi tambahan pegangan, dan merubah bentuk pegangan disesuaikan dengan dimensi tubuh (antropometri) operator TBS.

Pemakaian tojok hasil rancangan pada kegiatan sortasi TBS menunjukkan terjadinya penurunan keluhan rasa sakit (MSDs) berupa turunnya skor sedangkan pada kegiatan menaikkan TBS ke truk menunjukkan peningkatan keluhan rasa sakit berupa kenaikan skor.

\section{Daftar Pustaka}

Anizar, (2014). Ergonomic Work Facilities Design to Reduce Musculoskeletal Disorders Among Chips Worker, Joint International Conference APCHI-ERGOFUTURE-PEI-IAIFI 2014, Denpasar, AC46.

Cohen, L. (1995). Quality Function Deployment: How to Make QFD Work for You, USA : Addison-Wesley Publishing Company, p :11
Cross, N. (1996). Engineering Design Methods: Strategies for Product Design. New York: John Wiley dan Sons.

David, GC. (2005). Ergonomics Methods for Assessing Exposure to Risk Factor for Work Related Musculoskeletal Disorders, Occupational Medicine Volume 55, 190-199.

Grandjean, E.(1993). Fitting The Task to The Man: a Textbook of Occupational Ergonomics, $4^{\text {th }}$ Edition, Great Britain : Taylor \& Francis Ltd.

Iridiastadi, H, Yassierli. (2014). Ergonomi Suatu Pengantar, PT. Remaja Rosdakarya, Bandung.

Karmila, A.(2014). Keluhan Rasa Sakit yang dialami Operator Bagian Sortasi di PT. Perkebunan Kabupaten Langkat Sumatera Utara, Laporan Kerja Praktek Departemen Teknik Industri, Fakultas Teknik, Universitas Sumatera Utara.

Rajuli, Gazali, M., Surya, R.Z., (2014). Redesain Hook-t Muat Sawit untuk Mengurangi Tingkat Keluhan Musculuskletal Menggunakan Metode Quality Function Deployment (QFD) pada Sentra Pembelian Kelapa Sawit di P.Palas Kab. Indragiri Hilir, Riau. Seminar Nasional Statistika, Matematika dan Aplikasinya, Bandung : Unisba, 41-46.

Surya, R.Z., M. Gasali. (2014). Pemanfaatan Ergonomi dalam Kegiatan Pascapanen Kelapa Sawit untuk Mengurangi Keluhan Muskuloskeletal Petani. Statistika, Vol. 14 No.2, 87-92.

Tarwaka, dkk. (2004). Ergonomi Untuk Keselamatan, Kesehatan Kerja dan produktivitas. Surakarta: Unibas Press.

Kuorinka, I., Jonsson, B., Kilbom, A., Vinterberg, H., Biering-Sorensen, F., Andersson G., Jorgensen, K.(1987). Standardised Nordic Questionnaores (Applied Ergonomics)

Philips, C.A.. (2000). Human Factors Engineering. New York: John Wiley dan Sons.

Stanton, N.. (2005). Handbook of Human Factors and Ergonomics Methods, New York: CRC Press LLC.

Ergonomic Risk Assessment, 2004, Bulletin no. 239, http://www.gov.mb.ca./labour/safety/ergonomics/inde x.html 